\title{
INCOMPLETE LEFT BUNDLE-BRANCH BLOCK
}

\author{
BY \\ L. SCHAMROTH AND B. A. BRADLOW \\ From the Baragwanath Hospital, General Hospital and the University of the Witwatersrand, \\ Johannesburg, South Africa
}

Bundle-branch block dependent upon critical rate is a form of phasic aberrant ventricular conduction (Schamroth and Chesler, 1963). In this arrhythmia, bundle-branch block appears when the rate increases and disappears when it slows. The basis of this arrhythmia, as with all other forms of phasic aberrant ventricular conduction, is the presence of unequal refractory periods of the bundle branches. With relatively slow heart rates (illustrated as R1 to R2 in Fig. 1), consecutive impulses find both bundle branches fully recovered and normal intraventricular conduction ensues. With an increase in heart rate (illustrated as R1 to R3 in Fig. 1), consecutive impulses find one bundle branch-usually the right-refractory and the other fully recovered; conduction to the ventricles thus proceeds through one bundle branch only, resulting in an aberrant or bundlebranch block pattern.

Examples of this arrhythmia have been reported by Vesell (1941), Shearn and Rytand (1953), and Gardberg and Rosen (1958): in all these cases the transition from the bundle-branch block pattern to normal intraventricular conduction and vice-versa was sudden. We report another example of this arrhythmia where the aberrant pattern was in the form of left bundle-branch block and the transition from normal to aberrant conduction was gradual; this presented a unique opportunity to prove the clinical existence of incomplete left bundle-branch block and to study the various grades of incomplete left bundle-branch block clinically-a procedure that has hitherto been possible only in the experimental animal.

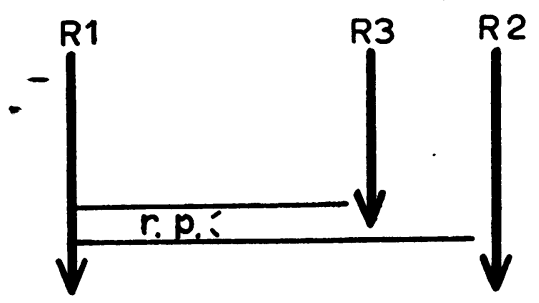

Fig. 1.-Diagrammatic representation of unequal refractoriness of the bundle branches and the effect on subsequent impulse formation. r.p. =refractory period of the bundle branches. (See text.)

\section{Case Report}

The electrocardiograms are those of a 49-year-old woman with angina pectoris. The records (Fig. 2 and 3) show fluctuation of the QRST patterns between normal intraventricular conduction and a left bundlebranch block pattern. The bundle-branch block pattern appears with an increase in heart rate and disappears with a decrease in heart rate; the transitions are gradual, revealing various degrees of incomplete left bundle-branch block. These fluctuations were seen repeatedly during long continuous recordings. 


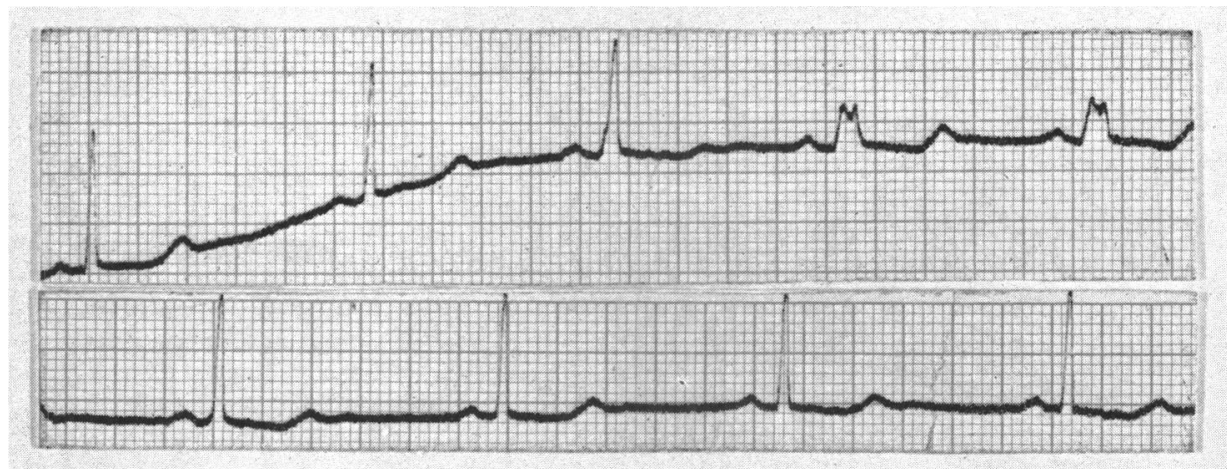

FIG. 2.-Cardiogram (continuous strip of lead V5) showing normal intraventricular conduction with a relatively slow rate and bundle-branch block with a faster rate. The transition from normal to abnormal intraventricular conduction is gradual, demonstrating various degrees of incomplete left bundle-branch block. (See text.)

\section{Discussion}

To establish convincing clinical evidence of incomplete bundle-branch block, it is necessary to demonstrate in the same patient: $(a)$ tracings with normal intraventricular conduction; $(b)$ subsequent tracings that show various degrees of incomplete bundle-branch block; and $(c)$ tracings that eventually show complete bundle-branch block. Furthermore, these transitions should be demonstrated during a short time interval. While these criteria have been amply fulfilled in the case of incomplete right bundle-branch block, there has as yet been no convincing clinical evidence to prove the existence of incomplete left bundle-branch block. Thus Grant (1957) states: “... the proof that a given conduction defect is due to a lesion of the left main bundle in man depends upon demonstrating that the prolongation was sudden in onset, and associated with a change in the direction of the initial forces of the QRS interval" and further, "... so far there have been no cases published of QRS prolongation to only 0.10 to $0.11 \mathrm{sec}$. of the leftward type with pre-block and post-block tracings to prove that a lesion of the left main bundle was indeed responsible".

Experimentally, however, the presence of incomplete left bundle-branch block has been demonstrated. Rodriguez and Sodi-Pallares (1952) and Sodi-Pallares et al. (1950), on the basis of experimental evidence, have described various degrees of incomplete left bundle-branch block. The first evidence of such block is the loss of the initial $q$ wave and the presence of slurring of the lower part of the upstroke of the $R$ wave in leads oriented to the left ventricle, i.e., leads I, AVL, V5, and V6: the $T$ wave may be either upright or inverted. There is thus a change in the direction of the initial vector. As the degree of block progresses, the $T$ wave becomes inverted and the initial slurring becomes greater and ascends the proximal limb of the QRS complex. As the bundlebranch block becomes complete, the QRS complex widens and develops a plateau which eventually becomes notched.

The loss of the initial $q$ wave and the development of slurring of the $\mathrm{R}$ wave is ascribed by SodiPallares and his associates (1950) to a delay in the activation of the left septal mass by the left bundle branch; and, with increasing block, to activation of the left septal mass by impulses from the right bundle branch. These authors also stress that although the intrinsicoid deflection generally measures more than $0.045 \mathrm{sec}$., the measurement is without significance in establishing the degree of block-morphology being the more important diagnostic criterion.

These experimental findings are amply confirmed by our case. Fig. 2 shows the transition from normal conduction to complete left bundle-branch block followed by a return to normal intraventricular conduction. The first complex shows normal intraventricular conduction with a small initial $\mathrm{q}$ wave; the intrinsicoid deflection measures $0.04 \mathrm{sec}$. The second complex shows the dis- 


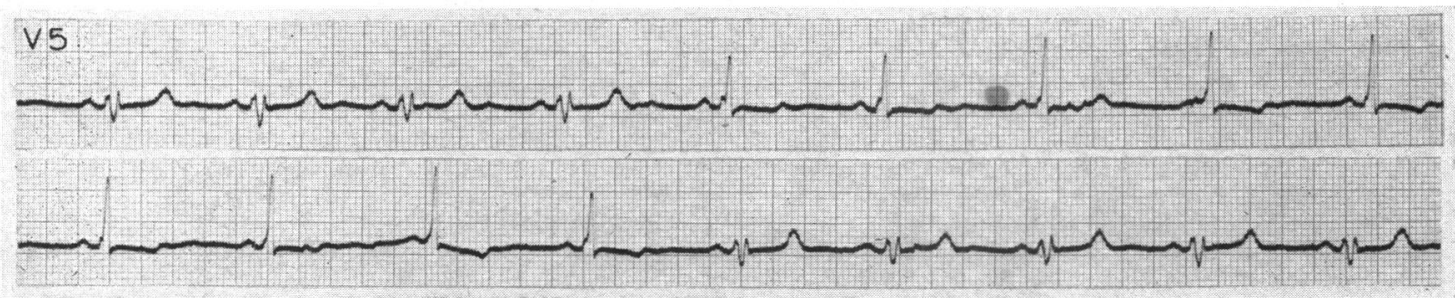

FIG. 3.-Cardiogram (continuous strip of lead V5) showing almost normal intraventricular conduction with a relatively slow rate and bundle-branch block with a faster rate. (See text.)

appearance of the initial $q$ wave and slight slurring of the lower part of the $\mathbf{R}$ wave; the intrinsicoid deflection measures $0.04 \mathrm{sec}$. The third complex shows prominent slurring of the ascending limb of the QRS complex with a delay in the onset of the intrinsicoid deflection to $0.07 \mathrm{sec}$. The fourth and fifth complexes show complete left bundle-branch block. The sixth to eighth complexes show the return to normal intraventricular conduction, and the small initial $\mathrm{q}$ wave is again visible in the last complex. Fig. 3 shows the same phenomenon: the varying degrees of slurring of the ascending limb of the QRS complex during the phase of incomplete left bundle-branch block are well seen. Fig. 4 shows various QRS complexes that have been extrapolated from lead V5 during the same recording and arranged so as to demonstrate the gradual development of the left bundle-branch block pattern. Complex 1 shows normal intraventricular conduction: note the small initial $\mathrm{q}$ wave. Complexes 2 to 5 show the development of incomplete left bundle-branch block: the initial $\mathrm{q}$ wave disappears, slurring ascends the proximal limb of the QRS complex, and the T wave becomes inverted. Complexes 6 to 9 represent increasing degrees of "complete" left bundle-branch block; complex 6 is widened to $0.12 \mathrm{sec}$., and is plateau shaped with a small notch in the plateau; there are, however, further apparent degrees of "complete" bundle-branch block for the QRS complex becomes wider and the notch deeper.

\section{Summary}

A case is described of left bundle-branch block dependent upon critical rate. The transition from normal conduction to complete left bundle-branch block was gradual, thus providing, for the first time, clinical evidence for the existence of incomplete left bundle-branch block.
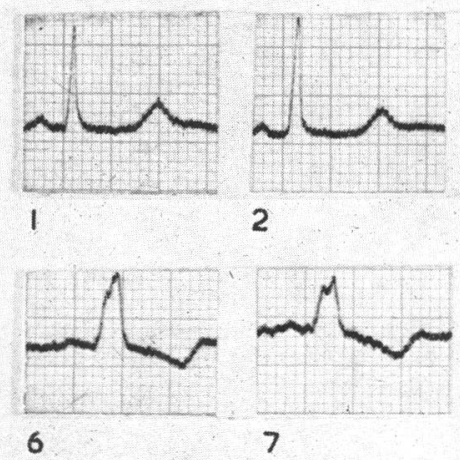

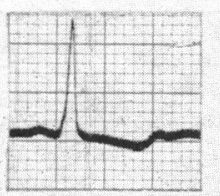

3

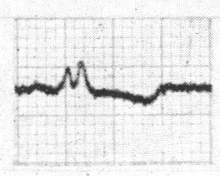

8

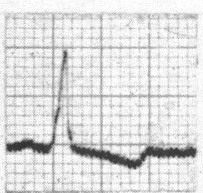

4

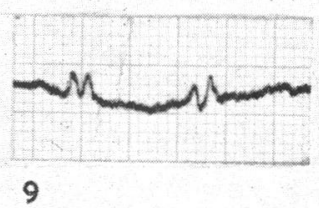

FIG. 4.-QRS complexes extrapolated from a continuous recording of lead V5 during intermittent left bundle-branch block and arranged so as to demonstrate the gradual development of the left bundle-branch block pattern. (See text.) 
We wish to express our thanks to the Photographic Department, Department of Medicine, University of the Witwatersrand, for the photographic reproductions.

\section{References}

Gardberg, M., and Rosen, I. L. (1958). Observations on conduction in a case of intermittent left bundle branch block. Amer. Heart J., 55, 677.

Grant, R. (1957). Clinical Electrocardiography, p. 126. McGraw-Hill, New York.

Rodriguez, M. I., and Sodi-Pallares, D. (1952). The mechanism of complete and incomplete bundle branch block. Amer. Heart J., 44, 715.

Schamroth, L., and Chesler, E. (1963). Phasic aberrant ventricular conduction. Brit. Heart J., 25, 219.

Shearn, M. A., and Rytand, D. A. (1953). Intermittent bundle-branch block; observations with special reference to the critical heart rate. Arch. intern. Med., 91, 448.

Sodi-Pallares, D., Estandia, A., Soberón, J., and Rodriguez, M. I. (1950). The left intraventricular potential of the human heart. II. Criteria for diagnosis of incomplete bundle branch block. Amer. Heart J., 40, 655 .

Vesell, H. (1941). Critical rates in ventricular conduction: Unstable bundle branch block. Amer. J. med. Sci., 202, 198. 